\title{
Factors Related to the Mental Health and Suicidal thoughts of Adults Living in Shelters for a Protracted Period Following a Large-Scale Disaster
}

Manami Amagai

Noriko Kobayashi

Mayumi Nitta

National College of Nursing, Tokyo, Japan

Email: amagaim@adm.ncn.ac.jp

Makiko Takahashi

Miyoshi Town Office

Ikuko Takada

Yumiko Takeuch

Yumiko Sawada

Okuma Town Office

Mayo Hiroshima

Division of Nursing, Tokyo Healthcare University Faculty of Healthcare

Doi:10.5901/ajis.2014.v3n3p11

Email: m-hiroshima@thcu.ac.jp

\begin{abstract}
After the Great East Japan Earthquake in March 2011, residents of the area affected by the Fukushima nuclear accident were forced to seek long-term shelter. International attention to mental health needs has increased along with reconstruction of life throughout the region. Mental health, suicidal thoughts and related factors in the 18 months after the Great East Japan Earthquake and Fukushima Daiichi Nuclear Disaster were examined in a community-based, cross-sectional study of 1,595 adults living in Fukushima. To determine mental status, we used the Japanese version of K6, which was developed to screen mood and anxiety disorders. Using a cut-off of 13 points, the frequency of poor mental health was $12.1 \%$ among all subjects. Thus, the frequencies of mental health problems and suicidal thoughts were high among residents forced to live in long-term shelters following a disaster. To improve the mental well-being of community-dwelling adults living for extended periods in shelters following a disaster, there is a need to focus on issues of unemployment, stress on the health of shelter dwellers and their families, stress on human relationships, social support, social capital, and suicidal thoughts.
\end{abstract}

Keywords: Mental health; Refugee, Earthquake; Nuclear disaster; suicidal thoughts

\section{Introduction}

The Great East Japan Earthquake in Japan on March 11, 2011 was a magnitude 9. It resulted in extensive damage and a tsunami that killed approximately 15,886 people, with a further 2,620 missing people (Police Agency, 2014). In the wake of the earthquake, residents of the affected area suffered from repeated aftershocks and from radiation as a result of the Fukushima nuclear incident, and 260,000 people are still living in long-term shelters (Reconstruction Agency, 2014a). The difficulties of rebuilding the lives of people living in a neighborhood or community that is highly disrupted or traumatized are risk factors that contribute to deterioration of mental health (Norris et al., 2002). At two post-accident sites, Chernobyl and Three Mile Island, communities have had to cope with the long-term subjective health concerns of residents and stress, with the result that mental health has become an important issue in public health (IAEA, 2006). Similarly, it is likely 
that the mental health of residents will become the most important issue in the long term following the Fukushima nuclear disaster (Bromet, 2012).

In Japan, mental health after a natural disaster has been a concern since the great Hanshin-Awaji earthquake in 1995. Suzuki et al. (2011) indicated that the percentage of community-dwelling elderly persons with subclinical mental health symptoms was high despite the low prevalence of mental disorders in the 3-year period after the Niigata-Chuetsu earthquake. In Japan, the suicide rate is about 30,000 per year, and health promotion and suicide prevention have become efforts of society as a whole. Various factors are relevant to suicide, including stressful daily life events in the past six months, a lack of a social network, economical factors, health conditions, awareness of people in the community, and mass media influence (Kawakami et al., 2007; Sakamoto, 2006; Motohashi, 2009).

Understand the prevailing situation is urgently needed to prevent suicide and secondary mental health issues in people already burdened by repeated aftershocks and radiation exposure. Therefore, the aim of this study is to explore the suicidal thoughts, mental health status and related factors in residents who have no option but to live in long-term shelters.

\section{Research Methodology}

\subsection{Participants and Procedures}

A community-based, cross-sectional study of 1,595 residents of long-term shelters was conducted in Fukushima Prefecture, Japan. From October 2012 to March 2013, a questionnaire was mailed to residents, who were asked to fill in and return the questionnaire. Valid responses were received from 1,109 recipients who answered all items in the questionnaire (effective response rate: 69.5\%). The study was approved by the medical ethics committee.

\subsection{Variables/measurements}

The questionnaire included the following items:

Main outcome: To determine the mental health status of participants, we used the Japanese version of K6 (Kawakami, 2005; Furukawa, 2003), which was developed to screen mood and anxiety disorders. The respondents could choose answers from a five-point Likert scale: 0-Not at all, 1-Seldom, 2-Sometimes, 3-Usually, and 4-Always. The total of the scores for six items (0 to 24 points each) was calculated. A higher score indicates a lower level of mental health. Based on the $\mathrm{K} 6$ scores, with a cut-off of 13 points, the participants were divided into two groups: those with good mental health (scores $<13$ points) and those with poor mental health (scores $\geq 13$ points). The suicidality module includes questions to assess the presence of suicidal thoughts in the last year (Did you think that you wanted to be dead in the last year?), and of suicidal thoughts in the past (Did you think that you wanted to be dead in the past?). We used instruments developed by Motohashi et al. (2005) to measure social capital. Questions were asked on five items: 1) mutual assistance and trust, 2) sense of social responsibility, 3) community attachment and identity, 4) interpersonal bonds, and 5) kindness of the community. The answers were scored on a four-point Likert scale: 0-Not at all, 1-Seldom, 2Sometimes, and 3-Often. In this study, total scores were calculated by adding the scores of the five items (0 to 15 points each). A higher total score indicated a stronger level of social capital.

Predictors: Questions were asked on (1) demographic profile, including gender, age, marital status and family members; (2) disaster-related factors, including area of residence, change in economic situation; (3) pre-disaster factors, including thoughts of wanting to die in the past; and (4) post-disaster factors, including current stress, coping with stress, social support, and social capital.

We examined whether the mental health status of the respondents differed with respect to demographics, social support, social capital, changes in economic conditions, stress, availability of ways to relieve stress, and suicidal thoughts.

\subsection{Data Analyses}

IBM SPSS Statistics 19 was used for statistical analysis. Descriptive statistics were used to measure the mental health status of the participants. Analysis was performed to determine how this status differed with respect to demographics, social support, social capital, changes in economic conditions, stress, availability of ways to relieve stress, and suicidal thoughts. Comparisons between groups with good and poor mental health were performed by $\div 2$ test and t-test. A Pearson product-moment correlation coefficient was calculated between mental sanity level (K6) and suicidal thoughts 
over the past 12 months and previously.

Multiple logistic regression analysis was performed to identify variables related to poor mental health. Variables with a significant association with mental health were identified at the $5 \%$ probability level in univariate analysis. The absence of multicolinearity among these variables was shown based on calculation of a Spearman correlation coefficient of $\leq 0.3$. In logistic regression analysis, $p<0.05$ in a two-tailed test was considered to indicate a significant relationship. The study was performed after approval of the institutional ethics committee.

\section{Results}

\subsection{Demographic characteristics of the subjects}

The demographic characteristics of the subjects are summarized in Table 1. The subjects were 434 men (39.1\%) and 675 women (60.9\%). The average age was $57.6 \pm 14.4(20-90)$ and $31.9 \%$ of the subjects were in their 60 s. Most of the subjects lived in A-city, lived with a family member, were unemployed, and had a worse economic situation after the disaster.

Table 1. Characteristics of the subjects

\begin{tabular}{|c|c|c|c|c|c|c|c|}
\hline \multirow{2}{*}{ Item } & & \multicolumn{2}{|l|}{ All } & \multicolumn{2}{|l|}{ Male } & \multicolumn{2}{|l|}{ Female } \\
\hline & & Number of people & $\%$ & Number of people & $\%$ & Number of people & $\%$ \\
\hline \multirow{8}{*}{ Age } & $20 \mathrm{~s}$ & 42 & 3.8 & 4 & 0.9 & 38 & 5.6 \\
\hline & $30 \mathrm{~s}$ & 113 & 10.2 & 18 & 4.1 & 95 & 14.1 \\
\hline & $40 \mathrm{~s}$ & 154 & 13.9 & 48 & 11.1 & 106 & 15.7 \\
\hline & $50 \mathrm{~s}$ & 213 & 19.2 & 60 & 13.8 & 153 & 22.7 \\
\hline & $60 \mathrm{~s}$ & 354 & 31.9 & 179 & 41.2 & 175 & 25.9 \\
\hline & $70 \mathrm{~s}$ & 180 & 16.2 & 100 & 23.0 & 80 & 11.9 \\
\hline & 80 and above & 53 & 4.8 & 25 & 5.8 & 28 & 4.1 \\
\hline & Total & 1109 & 100.0 & 434 & $100 \%$ & 675 & 100.0 \\
\hline \multirow{4}{*}{ Area of residence } & A-city & 492 & 44.4 & 198 & 45.5 & 294 & 43.6 \\
\hline & B-city & 403 & 36.3 & 147 & 33.8 & 256 & 38.0 \\
\hline & Other than $A / B$ & 214 & 19.3 & 90 & 20.7 & 124 & 18.4 \\
\hline & Total & 1109 & 100.0 & 435 & $100 . \%$ & 674 & 100.0 \\
\hline \multirow{3}{*}{ Family members } & Absence & 137 & 12.8 & 59 & 14.4 & 78 & 11.9 \\
\hline & Presence & 931 & 87.2 & 352 & 85.2 & 579 & 88.1 \\
\hline & Total & 1068 & 100.0 & 411 & 100.0 & 657 & 100.0 \\
\hline \multirow{3}{*}{ Occupation after the earthquake } & Employed & 361 & 34.2 & 81 & 20.1 & 280 & 42.9 \\
\hline & Unemployed & 695 & 65.8 & 322 & 79.9 & 373 & 57.1 \\
\hline & Total & 1056 & 100.0 & 403 & 100.0 & 653 & 100.0 \\
\hline \multirow{5}{*}{$\begin{array}{l}\text { Change in economic situation after the } \\
\text { disaster }\end{array}$} & Worse & 518 & 47.8 & 220 & 52.0 & 298 & 45.2 \\
\hline & Better & 62 & 5.7 & 14 & 3.3 & 48 & 7.3 \\
\hline & No change & 484 & 44.7 & 181 & 42.8 & 303 & 45.9 \\
\hline & Others & 19 & 1.8 & 8 & 1.9 & 11 & 1.7 \\
\hline & Total & 1083 & 100.0 & 423 & $100 . \%$ & 660 & 100.0 \\
\hline
\end{tabular}

\subsection{Post-disaster mental sanity (K6) and desire to die}

The average $\mathrm{K} 6$ score for mental health was $6.7 \pm 5.5$. A total of $189(12.1 \%)$ of the subjects were classified as having "severe" stress ( $K 6 \geq 13$ points). This rate of severe stress was significantly higher than the reported frequency of severe stress of $3 \%$ in the Japanese population (Kawakami, 2005). A total of 306 subjects (27.4\%) had experienced a desire to die in the last year. This rate was also significantly higher than the frequency of the desire to die in the Japanese population, which has been reported to be $22.7 \%$ (Cabinet office, 2012).

A matrix of Pearson product-moment correlation coefficients between mental sanity level (K6) and suicidal thoughts over the past 12 months and in the past is shown in Table 2. This analysis showed significant correlations between suicidal thoughts and mental sanity level. 
Table 2. Correlation coefficients between scores for mental health and the desire to die

\begin{tabular}{|c|c|c|c|c|c|c|c|}
\hline \multirow{2}{*}{ Item } & \multicolumn{7}{|c|}{ Scores for mental health (K6) } \\
\hline & Total score & K1 & K2 & K3 & K4 & K5 & K6 \\
\hline Desire to die in the last year & $0.508^{\star \star}$ & $0.362^{* *}$ & $0.470^{\star \star}$ & $0.398^{* \star}$ & $0.463^{\star \star}$ & $0.389 \star \star$ & $0.439 * \star$ \\
\hline Desire to die in the past & $0.296^{\star \star}$ & $0.227^{* *}$ & $0.220^{\star \star}$ & $0.230^{* *}$ & $0.263^{\star \star}$ & $0.223^{\star \star}$ & $0.316^{\star \star}$ \\
\hline
\end{tabular}

${ }^{*} p<0.05$ ** $p<0.01$

\subsection{Factors affecting mental health}

The subjects were divided into poor and good mental health groups to determine relevant factors in univariate analysis (Table 3). Items that showed a significant difference between the two groups included employment after the earthquake, changes in economic conditions, availability of people to listen to problems, material and/or monetary support, stress affecting the health of the subject or their family, relationship stress, environmental stress in the shelter, household stress, ways to relieve stress, social capital, and suicidal thoughts over the past 12 months. Thus, subjects with poor mental health were more likely to be unemployed after the earthquake; to be economically poor; to lack someone to listen to their problems; to lack material and/or financial support; to have lower social capital, health-related stress, relationship stress, stress in the shelter environment, household stress, and no way to relieve stress; and to have had suicidal thoughts over the past 12 months.

Table 3. Univariate analysis of scores for mental health with scores for attributes, changes in economic situation, stress, social support, and social capital.

\begin{tabular}{|c|c|c|c|c|c|c|}
\hline \multirow[t]{2}{*}{ Item } & & \multirow{2}{*}{$\begin{array}{c}\text { Number of } \\
\text { people }\end{array}$} & \multicolumn{2}{|c|}{$\begin{array}{c}\text { K6 Number of people } \\
(\%)\end{array}$} & \multirow[t]{2}{*}{$\div 2$} & \multirow[t]{2}{*}{$\mathrm{p}$} \\
\hline & & & $\mathrm{K} 6 \leq 12$ & $K 6 \geq 13$ & & \\
\hline \multirow{2}{*}{ Gender } & Male & 430 & $374(87.0)$ & $56(13.0)$ & \multirow[b]{2}{*}{0.992} & \multirow{2}{*}{0.334} \\
\hline & Female & 672 & \begin{tabular}{|l|}
$570(84.8)$ \\
\end{tabular} & 102(15.2) & & \\
\hline \multirow{3}{*}{ Area of residence } & $\mathrm{A}$ & 483 & \begin{tabular}{|l|}
$422(87.4)$ \\
\end{tabular} & $61(12.6)$ & \multirow{3}{*}{1.902} & \multirow{3}{*}{0.386} \\
\hline & $\mathrm{B}$ & 404 & $341(84.4)$ & $63(15.6)$ & & \\
\hline & Other than $A / B$ & 213 & $180(84.5)$ & $33(15.5)$ & & \\
\hline \multirow{7}{*}{ Age } & $20 \mathrm{~s}$ & 42 & $37(88.1)$ & $5(11.9)$ & \multirow{7}{*}{2.047} & \multirow{7}{*}{0.915} \\
\hline & $30 \mathrm{~s}$ & 113 & $97(85.8)$ & $16(14.2)$ & & \\
\hline & $40 \mathrm{~s}$ & 153 & $135(88.2)$ & $18(11.8)$ & & \\
\hline & $50 \mathrm{~s}$ & 213 & \begin{tabular}{|l|}
$179(84.0)$ \\
\end{tabular} & $34(16.0)$ & & \\
\hline & $60 \mathrm{~s}$ & 349 & \begin{tabular}{|l|}
$299(85.7)$ \\
\end{tabular} & $50(14.3)$ & & \\
\hline & $70 \mathrm{~s}$ & 178 & 154(86.5) & $24(13.5)$ & & \\
\hline & 80 and above & 51 & $42(82.4)$ & $9(17.6)$ & & \\
\hline \multirow{2}{*}{ Occupation after the earthquake } & Employed & 361 & $325(90.0)$ & $36(10.0)$ & \multirow{2}{*}{7.291} & \multirow{2}{*}{$0.007^{\star \star}$} \\
\hline & Unemployed & 685 & $575(83.9)$ & $110(16.1)$ & & \\
\hline \multirow{4}{*}{ Change in economic situation } & Worse & 512 & $412(80.5)$ & 100(19.5) & \multirow{4}{*}{19.532} & \multirow{4}{*}{$0.000^{* \star}$} \\
\hline & Better & 61 & $55(90.2)$ & $6(9.8)$ & & \\
\hline & No change & 483 & $435(90.1)$ & $48(9.9)$ & & \\
\hline & Others & 19 & $16(84.2)$ & $3(15.8)$ & & \\
\hline \multirow{2}{*}{ Stress on health of subject and family } & Yes & 689 & $559(81.1)$ & $130(18.9)$ & \multirow{2}{*}{31.028} & \multirow{2}{*}{$0.000^{* *}$} \\
\hline & No & 415 & \begin{tabular}{|l|}
$387(93.3)$ \\
\end{tabular} & $28(6.7)$ & & \\
\hline \multirow{2}{*}{ Stress with child-rearing } & Yes & 172 & $142(82.6)$ & $30(17.4)$ & \multirow{2}{*}{1.628} & \multirow{2}{*}{0.235} \\
\hline & No & 932 & \begin{tabular}{|l|}
$804(86.3)$ \\
\end{tabular} & $128(13.7)$ & & \\
\hline \multirow{2}{*}{ Stress with human relationships } & Yes & 366 & $285(77.9)$ & $81(22.1)$ & \multirow{2}{*}{27.299} & \multirow{2}{*}{$0.000^{* x}$} \\
\hline & No & 738 & $661(89.4)$ & $77(10.4)$ & & \\
\hline \multirow{2}{*}{ Living environment stress } & Yes & 445 & $356(80.0)$ & $89(20.0)$ & & $0000 * x$ \\
\hline & No & 659 & $590(89.5)$ & $69(10.5)$ & 19.670 & $0.000^{* x}$ \\
\hline Ctrocs with houshold & Yes & 382 & \begin{tabular}{|l|}
$307(80.4)$ \\
\end{tabular} & $75(19.6)$ & 12100 & 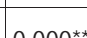 \\
\hline Stress with household & No & 722 & \begin{tabular}{|l|}
$639(88.5)$ \\
\end{tabular} & $83(11.5)$ & 13.490 & $0.000^{x x}+2-3$ \\
\hline People available to listen to subjects frustrations & Yes & 959 & $847(88.3)$ & 112(11.7) & 11270 & $0000 * x$ \\
\hline after the earthquake & No & 145 & $99(68.3)$ & $46(31.7)$ & 41.270 & $0.000^{x x}+2-3$ \\
\hline
\end{tabular}




\begin{tabular}{|c|c|c|c|c|c|c|}
\hline \multirow{2}{*}{$\begin{array}{l}\text { People who support subjects materially and/or } \\
\text { financially after the earthquake }\end{array}$} & Yes & 841 & 743(88.3) & 98(11.7) & \multirow{2}{*}{20.350} & \multirow{2}{*}{$0.000^{\star *}$} \\
\hline & No & 263 & 203(77.2) & $60(22.8)$ & & \\
\hline \multirow{2}{*}{ Availability of ways to relieve stress } & Yes & 998 & $863(86.5)$ & 135(13.5) & \multirow{2}{*}{5.217} & \multirow{2}{*}{0.02} \\
\hline & No & 106 & $83(78.3)$ & $23(21.7)$ & & \\
\hline Social capital & Total score (Mean \pm SD) & 1104 & $4.9 \pm 3.7$ & $6.9 \pm 3.5$ & $6.750^{\mathrm{a}}$ & $0.000^{* *}$ \\
\hline
\end{tabular}

${ }^{*} p<0.05^{* *} p<0.01$ at-test

Of the 12 variables that were significantly related to mental health in univariate analysis, 11 had multicolinearity coefficients of $\leq 0.3$ in Spearman correlation analysis. To examine whether these variables influenced mental health, logistic regression analysis was performed using the backward elimination method (Table 4). In this analysis, employment status after the earthquake, people to listen to problems, personal or family stress, human relationship stress, social capital, and suicidal thoughts over the past 12 months were found to be significantly associated with mental health. In this model, these factors accounted for $87.0 \%$ of the variation $\left(R^{2}=0.25\right)$ and thus can be used to identify persons who are likely to suffer from poor mental health after a disaster.

Table 4. Predictors of mental health after the earthquake (logistic regression analysis)

\begin{tabular}{|c|c|c|c|c|}
\hline Item & Category & Odds ratio & 95\% confidence interval & $\mathrm{p}$-value \\
\hline \multirow{2}{*}{ Employment status after the earthquake } & Unemployed & 1.000 & \multirow{2}{*}{$0.295-0.737$} & \multirow{2}{*}{$0.001^{\star \star}$} \\
\hline & Employed & 0.466 & & \\
\hline \multirow{2}{*}{ People available to listen to subjects' frustration } & No & 1.000 & \multirow{2}{*}{$0.196-0.518$} & \multirow{2}{*}{$0.000^{\star *}$} \\
\hline & Yes & 0.319 & & \\
\hline \multirow{2}{*}{ Stress with health of subject and family } & No & 1.000 & \multirow{2}{*}{$1.666-4.410$} & \multirow{2}{*}{$0.000^{\star \star}$} \\
\hline & Yes & 2.710 & & \\
\hline \multirow{2}{*}{ Stress with human relationships } & No & 1.000 & \multirow{2}{*}{$1.235-2.818$} & \multirow{2}{*}{$0.003^{\star \star}$} \\
\hline & Yes & 1.865 & & \\
\hline \multirow{2}{*}{ Suicidal thoughts over the past 12 months } & No & 1.000 & \multirow{2}{*}{$1.376-2.273$} & \multirow{2}{*}{$0.000^{* *}$} \\
\hline & Yes & 1.768 & & \\
\hline Social capital & & 0.861 & $0.810-0.914$ & $0.000^{\star \star}$ \\
\hline
\end{tabular}

Model $\div 2$-test ${ }^{* *} p<0.01$; Hosmer-Lemeshow test $p=0.627$; Predictive rate $87.0 \%$

\section{Discussion}

People forced to live in shelters for more than a year as a result of the Fukushima Daiichi Nuclear Disaster and the Great East Japan Earthquake had poorer mental health compared to the general population of Japan. Therefore, the risk for secondary mental health disorders is high in such people. To predict the likelihood of development of severe mental health disorders, it is important to understand whether a person has lost their job following earthquake disaster, has no one who will listen to their problems, worries about their own physical and mental health and that of their family, are in a situation where they have an attachment to a region, have poor interactions with residents who moved in after the earthquake, and who have thought about committing suicide.

In light of these findings, we suggest that regular mental health monitoring is important and that mental health surveys are integrated with physical health surveys. Monitoring of mental health has previously been recommended after a disaster (Norris et al., 2002). The subjects in this study are likely to have prolonged stress of various types because they are in a situation with little prospect of returning to normal life. It would be useful to continue with a consultation support system to avoid victims of a disaster being cornered emotionally. Also, with respect to suicide prevention, ties with friends living in a familiar area are important (Oka et al, 2011). Stimulation of good interactions between local residents and refugees is also important, along with building a life network aimed at prevention of mental illness.

\section{Conclusion}

This study showed that that the frequency of mental health problems was high among residents forced to live in long-term shelters following a disaster. The mental health status was found to be related to matters such as employment status after the disaster, the presence of people who will listen to problems, formation of social norms and bonds among a local community that has been displaced, stress on human relationships and health, and thoughts of suicide in the past. There 
is a need for continued and new social support to promote psychological recovery of adults living in long-term shelters. It is desirable to monitor the mental health of refugees on a regular basis and to give emotional support, material support to help with economic hardship, and support for building connections in the community.

\section{References}

Bromet, Evelyn.(2012). Reflections on the mental health consequences of nuclear power plant disasters and implications for epidemiologic research in Northeast Japan, Japanese Bulletin of Social Psychiatry 21(2), 222-234.

Furukawa, T. (2003). Study on Convenient Screening for Mental Health in the General Population. The 2002 Health and Labour Sciences Research Grants (MHLW Special Research Projects). "Study on the current state of mental health problems and its infrastructure measures." Cooperative Study Report. Retrieved from mental.m.u-tokyo.ac.jp/h14tokubetsu/ SharedStudyReport22.pdf

IAEA (International Atomic Energy Agency).(2006). Chernobyl's Legacy: Health, Environmental and Socio-economic Impacts. Vienna, Austria, The Chernobyl Forum.2003-2005.

Kawakami, N. (2005). Study on mental health related to suicide prevention measures for adults. The 2004 MHLW Grants System Mental Health Science. "Study on promotion of preventive measures based on the current status of suicide." Shared Study Report.

http://ikiru.ncnp.go.jp/ikiru-hp/report/ueda16/ueda16-8.pdf website.

Kawakami N. (2007). Review of the pilot study on psychological autopsy evaluation: Analysis of factors related to suicide by case-control study. The 2006 MHLW Grants System Mental Health Science. "Study on promotion of preventive measures based on the current status of suicide." General study report. http://ikiru.ncnp.go.jplikiru-hp/report/ueda18/ueda18-1.pdf website.

Motohashi Y., Kaneko Y., \& Yamaji M. (2005). Social capital and suicide prevention. Akita Journal of Public Health, 3(1), 21-31.

Motohashi Y. (2009). Study for effectiveness of community-based suicide prevention - Construction of social capital model -. The 2007 business year report of the Grant-in-Aid for Scientific Research by Ministry of Education, Science, Sports and Culture. http://kaken.nii.ac.jp/pdf/2009/seika/jsps-1/11401/18390193seika.pdf

National Police Agency of Japan. (2014). Damage Situation and Police Countermeasures associated with 2011Tohoku district - off the Pacific Ocean Earthquake. May 9, 2014. http://www.npa.go.jp/archive/keibi/biki/higaijokyo.pdf website.

Norris, H., Friedman, J., Watson, J., Byrne, M., Diaz, E., \& Kaniasty, K.(2002). 60,000 disaster victims speak: Part I. An empirical review of the empirical literature, 1981-2001. Psychiatry 65(3), 207-39.

Oka, D., \& Yamauti K. (2011). The Search for Suicide-prevention Factors in an Area with Low Suicide Rates. , Japanese Bulletin of Social Psychiatry 20(3), 213-223.

Reconstruction Agency of Japan.(2014). Number of evacuees, such as national. May 9, 2014. http://reconstruction.go.jp/topics/post.html website.

Sakamoto, S. (2006). Psychology/social causes of suicide: What should be taken into consideration for suicide prevention. The Japanese Journal of Stress Sciences, 21(1), 42-53.

Suzuki, Y., Tsutsumi, A., Fukazawa, M., Honma H., Someya T., \& Kim, Y.( 2011). Prevalence of mental disorders and suicidal thoughts among community-dwelling elderly adults 3 years after the Niigata-Chuetsu Earthquake. Journal of Epidemiology 21(2), 144-150. 